\title{
Learning from women about HIV risk, HIV testing behaviors, and prevention practices in Mpumalanga, South Africa: A descriptive study to inform microbicides introduction
}

\author{
Martha Brady \\ Population Council \\ Saiqa Mullick \\ Population Council \\ Barbara Friedland \\ Population Council \\ Marlena Gehret Plagianos \\ Population Council \\ Linda Du Plessis
}

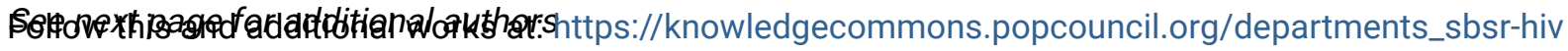

Part of the Demography, Population, and Ecology Commons, Family, Life Course, and Society Commons, Gender and Sexuality Commons, International Public Health Commons, and the Women's Health Commons How does access to this work benefit you? Let us know!

\section{Recommended Citation}

Brady, Martha, Saiqa Mullick, Barbara Friedland, Marlena Gehret Plagianos, Linda Du Plessis, and Thabiso Mango. 2015. "Learning from women about HIV risk, HIV testing behaviors, and prevention practices in Mpumalanga, South Africa: A descriptive study to inform microbicides introduction." New York: Population Council. 


\section{Authors}

Martha Brady, Saiqa Mullick, Barbara Friedland, Marlena Gehret Plagianos, Linda Du Plessis, and Thabiso Mango 
LEARNING FROM WOMEN ABOUT HIV RISK, HIV TESTING BEHAVIORS, AND PREVENTION PRACTICES IN MPUMALANGA, SOUTH AFRICA: A DESCRIPTIVE STUDY TO INFORM MICROBICIDES INTRODUCTION 



\section{Learning from Women about HIV Risk, HIV Testing Behaviors, and Prevention Practices in Mpumalanga, South Africa: A Descriptive Study to Inform Microbicides Introduction}

Martha Brady, Saiqa Mullick, Barbara Friedland, Marlena Plagianos, Linda Du Plessis, and Thabiso Mango 
This activity was made possible by the generous support of the American people through the United States Agency for International Development (USAID) under the terms of Cooperative Agreement No. GPO-A-00-0400019-00. The contents are the sole responsibility of the Population Council and do not necessarily reflect the views of USAID or the United States Government.

The Population Council confronts critical health and development issuesfrom stopping the spread of HIV to improving reproductive health and ensuring that young people lead full and productive lives. Through biomedical, social science, and public health research in 50 countries, we work with our partners to deliver solutions that lead to more effective policies, programs, and technologies that improve lives around the world. Established in 1952 and headquartered in New York, the Council is a nongovernmental, nonprofit organization governed by an international board of trustees.

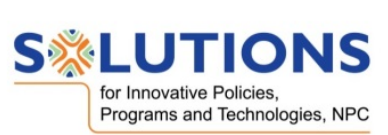

Solutions IPPT is a South African non-governmental organization (NGO), registered in 2011 as a non-profit company. Solutions IPPT specializes in providing technical assistance for policy development and reform, health systems strengthening/human resource capacity building, applied quantitative and qualitative research, M\&E and program design and management. Solutions IPPT works at various levels of government and the community in South Africa.

Population Council

One Dag Hammarskjold Plaza

New York, New York 10017 USA

Tel: 1-212-339-0500

Fax: 1-212-755-6052

popcouncil.org

Suggested citation: Brady, Martha, Saiqa Mullick, Barbara Friedland, Marlena Plagianos, Linda Du Plessis, and Thabiso Mango. 2015. "Learning from women about HIV risk, HIV testing behaviors, and prevention practices in Mpumalanga, South Africa: a descriptive study to inform microbicides introduction." New York: Population Council.

(C2015 The Population Council, Inc.

Any part of this publication may be photocopied without permission from the publisher provided that copies are distributed without charge and that full source citation is provided. The Population Council would appreciate receiving a copy of any materials in which the text is used. 


\section{Table of Contents}

Acknowledgments ... i

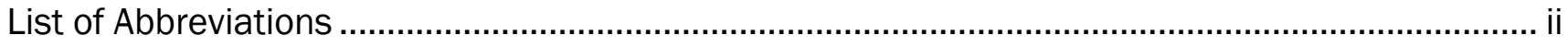

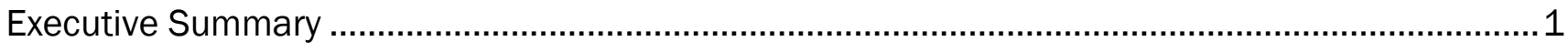

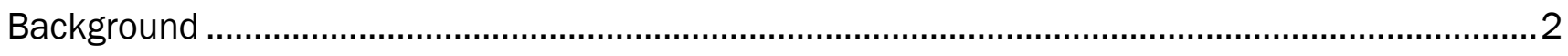

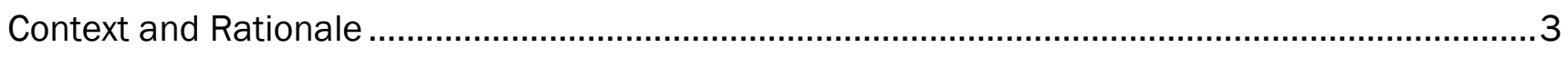

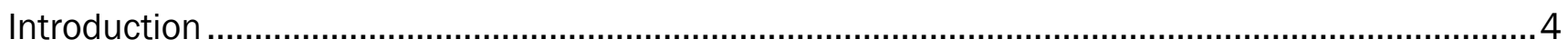

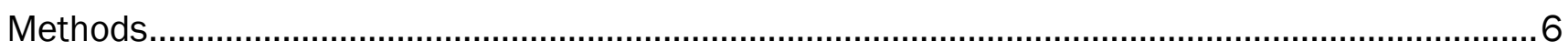

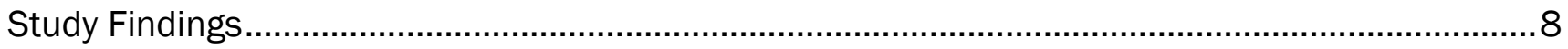

implications for Introduction of ARV-based Prevention Products for Women ............................. 17

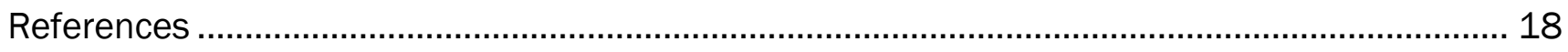

Appendix: Description of the Five Study Clinics................................................................. 19 



\section{Acknowledgments}

This report was prepared by staff at the Population Council (Martha Brady, Saiqa Mullick, * Barbara Friedland, and Marlena Plagianos) and Solutions for Innovative Policies, Programs and Technologies (Linda Du Plessis, Thabiso Mango, Xoliswa Keke, and Nokuthula Futwa). The authors would like to thank Virginia Kallianes and Siphiwe Mbobo for administrative assistance throughout the project, Sherry Hutchinson for design, and Boishoko Shoke for her research assistance at various stages. (*Dr. Saiqa Mullick was at the Population Council at the time the study was implemented; she is currently at Wits RHI.)

The Population Council and Solutions IPPT would like to acknowledge the Mpumalanga Department of Health for its commitment and support throughout the study. A special thank you goes to District Health and Primary Health Care Managers from three Mpumalanga districts (Ehlanzeni, Gert Sibande, and Nkangala), the Mpumalanga Department of Health Research and Ethics Committee, operational managers of the facilities, and fieldworkers in the three subdistricts and five clinics where the study was conducted for their undivided support in preparation of the sites and collection of the data for the study. Finally, the authors would like thank the women who participated in the study and gave generously of their time, energy, and perspectives, without whom this study would not have been possible. 


\section{List of Abbreviations}

ANC

ARV

CBO

CHW

CMR

DoH

EN

EPI

FACTS

FP

GA

$\mathrm{HCT}$

MD

MMC

NA

OC

PEP

PHC

PN

PNC

PrEP

$\mathrm{RH}$

$\mathrm{Rx}$

$\mathrm{SRH}$

SSI

STI

TB

VMMC
Antenatal care

Antiretroviral

Community-based organization

Community health worker

Composite measure of risk

Department of Health

Enrolled nurse

Expanded program on immunization

Follow-on African Consortium for Tenofovir Studies

Family planning

General assistant

HIV counseling and testing

Medical doctor

Medical male circumcision

Nursing assistant

Oral contraceptive

Post-exposure prophylaxis

Primary health care

Professional nurse

Postnatal care

Pre-exposure prophylaxis

Reproductive health

Prescription

Sexual and reproductive health

Semistructured interview

Sexually transmitted infection

Tuberculosis

Voluntary medical male circumcision 


\section{Executive Summary}

As the discussion continues around how best to provide HIV-prevention products and services to women, deepening the understanding of the service-delivery context and health-seeking behaviors of women provides a useful foundation upon which to build effective education and service-delivery efforts. The Population Council, in partnership with Solutions IPPT, conducted this study to learn more about women's experiences in routine primary health care (PHC) centers in Mpumalanga, South Africa, to inform microbicides introduction.

Based on the results of the CAPRISA 004 trial conducted in South Africa, which showed that use of 1 percent tenofovir gel, an antiretroviral (ARV)-based microbicide, resulted in a 39 percent reduction in risk of HIV infection among women (Abdool Karim et al. 2010), the international community began to prepare for the introduction of tenofovir into health systems. This study was conducted while FACTS 001, a trial designed to confirm the results of CAPRISA 004, was underway. Although the focus was on tenofovir vaginal gel as the potential product, the study sought to identify and highlight key programmatic, socio-behavioral, and user-related issues that are relevant to any ARV-based prevention product.

The provision of any new prevention product in clinical trial settings is often vastly different from implementation in "real life" public sector settings. In addition, use of ARVs, such as tenofovir gel, for pre-exposure prophylaxis (PrEP) will require regular HIV testing to ensure users are uninfected before initiating and continuing product use. Therefore, before any ARV-based prevention product can be introduced to women, information is needed on HIV testing practices, how best to integrate products into existing primary health care systems, including within sexual and reproductive health (SRH) and HIV-prevention services, and women's risk perception and health-seeking behaviors. This study explores these issues.

Key insights from this study discussed in detail in this report are as follows:

- Service seeking-Among the population of women attending PHC centers, the most commonly sought services of study participants were: well-baby (30 percent), family planning (FP) (17 percent), antenatal care (10 percent), and HIV testing and counseling (10 percent). These services may afford good opportunities to integrate new HIVprevention products as they become available.

- Constellation of services-The potential range of HIV-related services (prevention and treatment, care, and support) at PHC centers is impressive. There is variability in how these services are implemented; the comprehensiveness of services is uneven across study sites.

- HIV testing behavior-The vast majority of women (93 percent) reported having been tested for HIV at least once in their life. Among women who came for FP or well-baby services, 69 percent had been tested more than once in the previous year. Importantly, program managers and providers confirmed that women had been coming for testing.

- Self-assessment of risk-About one-fifth of women appeared to have a fairly accurate risk self-assessment based on a composite measure of risk (CMR) created from response to a battery of key questions. More than half either underestimated or did not know their risk based on the same CMR.

- Interest in tenofovir gel-While most women had not heard of tenofovir gel before this study, the majority reported "willingness to try" it if it were available. One-half of study participants said they would be willing to come for testing on a quarterly basis if it was required to access the product. 


\section{Background}

Despite recent declines in HIV incidence overall, the number of new infections among women remains high (UNAIDS 2014). The UNAIDS “Global Plan Towards the Elimination of New HIV Infections Among Children by 2015 and Keeping Their Mothers Alive" targeted a 50 percent reduction in HIV incidence among women of reproductive age (15-49 years old) between 2009 and 2015. By the end of 2013, however, incidence had only declined by 17 percent. Additional HIV-prevention strategies, including both biomedical and behavioral interventions, are clearly needed to achieve this goal.

Behavioral interventions, such as condom use and reduction of sexual partners, have contributed to the reduction in heterosexual transmission, yet many people are still at high risk (Steen et al. 2009). Biomedical interventions, such as voluntary medical male circumcision (VMMC) and use of antiretrovirals (ARV) for prevention, are now being introduced (PEPFAR 2011). Post-exposure prophylaxis (PEP) is available in several countries (AIDSTAR-One 2012), and the use of ARVs prior to exposure (PrEP) has been found effective in a number of settings (Grant et al. 2010; Baeten et al. 2012; Thigpen et al. 2012).

South Africa continues to be one of the countries hardest hit by HIV and AIDS, despite recent gains in treatment and prevention. According to UNAIDS, overall HIV prevalence in the general population is estimated at 17.9 percent (UNAIDS 2013). Of the 6.1 million people living with HIV, more than half are females 15 and older (UNAIDS 2013). 


\section{Context and Rationale}

In 2010, the CAPRISA 004 trial conducted in South Africa showed that use of 1 percent tenofovir gel, an ARVbased microbicide, resulted in a 39 percent reduction in risk of HIV infection among women (Abdool Karim et al. 2010). Based on these promising findings, the international community began preparing for the introduction of tenofovir gel (USAID 2011). However, the provision of a microbicide in clinical trial settings is vastly different from implementation in "real life" public sector settings, and important questions must be addressed, such as who to target for tenofovir gel, how it will be provided, and by whom. Before tenofovir gel or other ARV-based prevention products can be introduced to women, information is needed on HIV testing practices, how best to integrate products into existing primary health care (PHC) systems, including within sexual and reproductive health (SRH) and HIV-prevention services, and women's risk perception and healthseeking behaviors. 


\section{Introduction}

\section{STUDY OBJECTIVES}

The overall goal of this study was to pave the way for the introduction of tenofovir gel or other ARV-based prevention products for women by exploring the populations to target, the types of services through which tenofovir gel might be provided, by whom, and under what service-delivery conditions.

Specifically, the study objectives were to:

- Document the socio-demographics, HIV-risk perception, HIV testing behaviors, nature and frequency of potential HIV exposure, and use of HIV-prevention and SRH services among female clients at routine PHC services.

- Document clients' perspectives on ARV-based prevention and tenofovir gel specifically, including their interest and willingness to try such products in the future.

- Gather insights from a select number of facility and program managers about the potential role that tenofovir gel could play in their programs and the challenges and opportunities around its introduction.

\section{STUDY DESIGN}

A descriptive, cross-sectional study was carried out in five high-volume PHC facilities ${ }^{1}$ offering a range of HIV and/or SRH services in Mpumalanga, South Africa. Data were collected during a six-week period among clients through structured, quantitative, interviewer-administered face-to-face exit interviews and paper-based self-administered anonymous questionnaires. In addition, semi-structured interviews (SSIs) were conducted with a small number of provincial health program managers and service providers.

\section{STUDY SETTING}

Despite being the second smallest province in South Africa, Mpumalanga $\left(76,495 \mathrm{~km}^{2}\right.$; population 4,039,939 [Census 2011]), has the second highest HIV prevalence (35.1 percent) in the country (National Department of Health 2010). Figure 1 provides an illustration of the province with district and subdistrict demarcations.

${ }^{1}$ Family planning (FP), reproductive health (RH), and HIV counseling and testing (HCT) are provided within the service-delivery framework of PHC facilities in South Africa. 
FIGURE 1. HIV PREVALENCE ESTIMATES FOR MPUMALANGA, SOUTH AFRICA

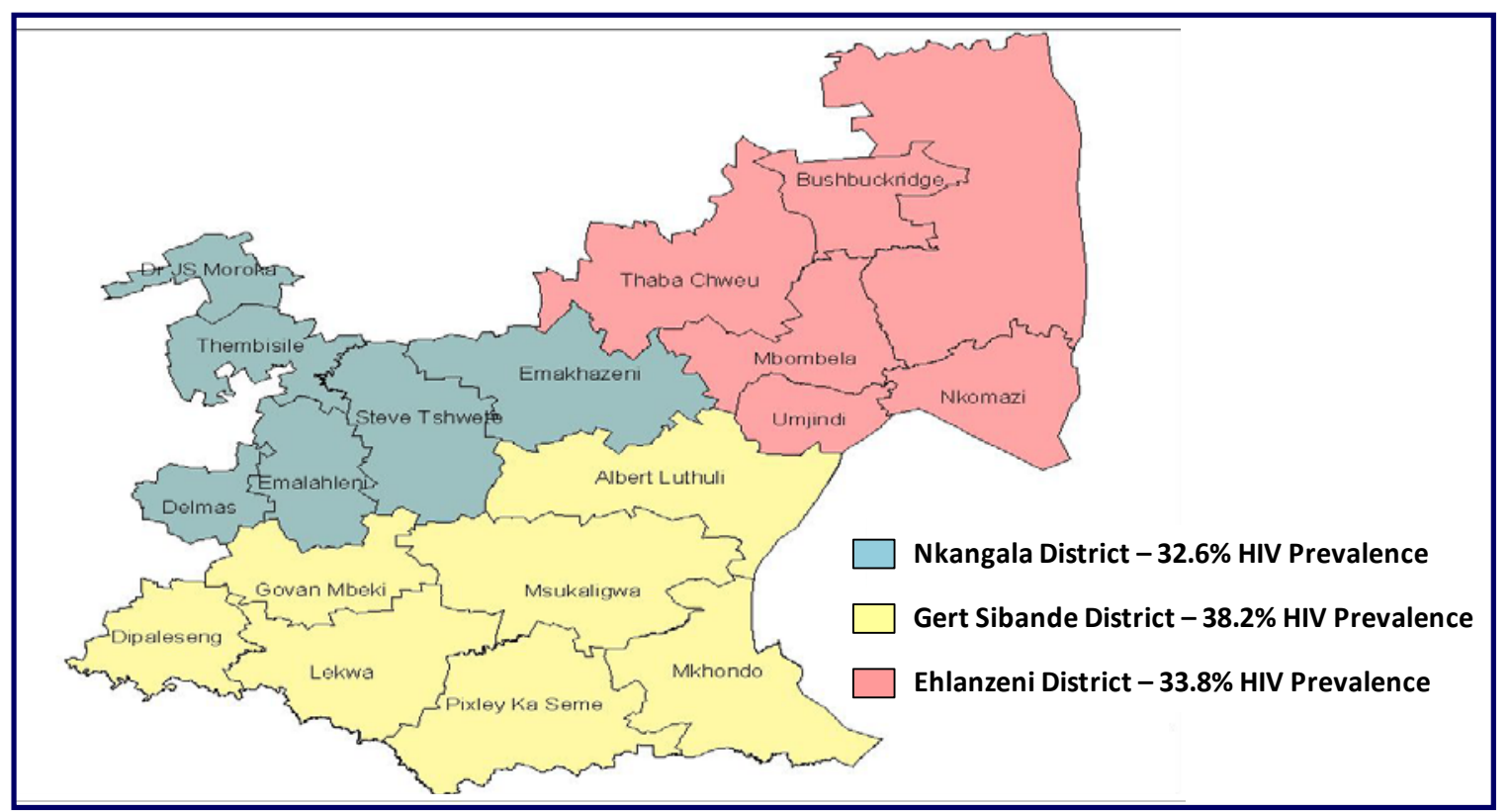

Map credit: South African Medical Research Council, 2014 


\section{Methods}

\section{SITE SELECTION}

High-volume facilities meeting the following criteria were selected: provide HIV testing services, HIV-prevention services, FP services, client load of $>200$ per month, and have more than two professional nurses on staff. A list of all facilities meeting these criteria was obtained from the provincial Department of Health (DoH) in Mpumalanga. At least four sites were required to enable the use of parametric measures for data analysis (Hayes and Moulton 2009). A target sample of six sites was randomly selected to achieve reasonable balance with regard to total client load, staff available, rural and urban location, and subdistrict. A statistician used a basic two-stage sampling procedure to randomly select sites for each district. After the clinics were selected, the Solutions IPPT team (Pretoria, South Africa) confirmed the choices in consultation with the district leadership, and after inspecting each site to ensure that it met the study criteria. Prior to study start, one of the selected clinics burned down; therefore, the study was implemented at five clinics.

\section{RESPONDENT SELECTION}

A convenience sample of women aged 18 or older accessing any type of health services (e.g., HIV counseling and testing [HCT], FP, antenatal care, well-baby) at any of the five PHC facilities during the six-week data-collection period were invited to participate in the study. Each day, fieldworkers approached all women who appeared to be 18 years of age or older who presented for any type of service. Clients were told about the study while they were waiting for the service(s) they had come for, and were asked if they were interested in participating. Those who agreed were asked to sign an informed consent form. Then, at the end of their clinic visit, women met with a fieldworker who conducted a standardized, face-to-face, structured exit interview. Women who took part in an exit interview were also asked if they would be willing to complete an anonymous self-administered questionnaire. Those who agreed completed the paper questionnaire, sealed it in the envelope provided, and placed it in a box on the way out of the facility.

Solutions IPPT staff invited the managers of each of the five study clinics as well as program managers at the district and provincial levels to participate in semistructured interviews (SSIs) conducted either in-person or by telephone .

\section{DATA COLLECTION}

A team of two fieldworkers was assigned to each facility, sharing the workload of recruiting and interviewing clients. Exit interviews contained questions about health-seeking behaviors, HIV testing practices, FP use, and reasons for attending the clinic on the day of the interview. On completion of the face-to-face exit interviews, women were asked to complete a self-administered anonymous questionnaire. This questionnaire captured sensitive information regarding sexual behavior that may be difficult to answer in a face-to-face interview format. Both questionnaires (exit interview and anonymous self-interview) were translated and, after pilot testing, back translated into the relevant local languages: Ndebele, Sepedi, Siswati, Tsonga, and Zulu. Clients were asked to choose their preferred interview language from the five local languages, or English. The SSIs, which were conducted by Solutions IPPT staff members using a standardized moderator's guide, were audio-recorded and transcribed by the Solutions IPPT team.

Data collection and management was coordinated by Solutions IPPT with oversight from the Population Council (Johannesburg, South Africa, and New York, NY, USA). A fieldworker-training workshop was held and included: (1) review of concepts of SRH and ARV-based HIV prevention, with an emphasis on tenofovir gel; (2) quantitative interviewing skills; (3) key considerations in conducting research on SRH and sexual practices; and (4) a thorough review of the instruments, including practice with mock interviews. The training highlighted the importance of confidentiality and informed consent in research. During the training, all fieldworkers completed an NIH research ethics course and certification test. Once data collection began, field supervisors based at Solutions IPPT traveled regularly to study sites to supervise data collection and carry out data quality checks. 


\section{DATA ANALYSIS}

Quantitative data from exit interviews and self-administered questionnaires were entered in Epi Info by the Solutions IPPT data manager. Field supervisors oversaw data entry, management, and data cleaning during the study. Data were exported from Epi Info into SAS (Version 9.4) for analysis. Responses to all questions from the exit interviews and the anonymous questionnaires were summarized, with frequency distributions for categorical responses, and mean, standard deviation, and range for numeric responses. Some numeric responses (such as age) were also grouped into categories for summarization. Numeric and categorical summaries were calculated for sociodemographic data within and across sites. Proportions were calculated for the percentage of clients who had been previously tested for HIV, who had heard of vaginal microbicides, and who reported that they would be interested in using a microbicide in the future. Chi-square tests were used to assess the associations between the service(s) women came for (per the exit interview) and their self-assessed level of HIV risk (per the anonymous questionnaire). Chi-square tests were also performed to identify significant differences between age groups for: ever tested for HIV, tested for HIV in the last year, and tested for HIV more than once in the last year.

Qualitative data from the SSIs with facility and program managers were analyzed thematically by the New Yorkbased study team.

\section{ETHICAL CONSIDERATIONS}

The study protocol was reviewed and approved by the Institutional Review Boards of the Population Council and the University of Witwatersrand in Johannesburg, South Africa, and by the Mpumalanga DoH. The informed consent process included a description of the study, procedures to be followed, possible discomforts and risks, benefits, compensation, and confidentiality. Women were informed that they would not benefit directly from participating in the study and that no monetary compensation would be provided. Women were also told that they had the right to withdraw from the study at any time or refuse to answer any questions that were uncomfortable for them. Clinic staff assisted in facilitating space for interviews, either in private rooms within the clinics, outdoors under trees, or in other private spaces. None of the data collected included personal identifiers. Study participants and records could be identified only by identification numbers assigned at the facility level or by a study number assigned by the research team. 


\section{Study Findings}

The study team aimed to interview 1,200 women in the specified data-collection period, which, due to budgetary and logistical constraints, was set at six weeks. During this data- collection period a total of 2,432 women were approached at the clinic sites and told about the study. Of those, 1,227 women (50 percent) enrolled and completed an exit interview and 991 of those women (80 percent) also completed a selfadministered anonymous questionnaire. It is noteworthy that interviews were conducted with women after they received services, which meant that their overall time spent at the clinic increased.

This report highlights select themes by study objectives. As shown in Table 1, the study population was fairly equally distributed at four of the five sites; the fifth site, Boulders clinic had fewer participants $(n=165 ; 13$ percent). Detailed information on the clinics can be found in the Appendix. The report highlights selected themes based on the study objectives.

\section{OBJECTIVE 1}

Document the sociodemographics, HIV risk perception, HIV testing behaviors, nature and frequency of potential HIV exposure, and use of HIV prevention and SRH services among female clients at routine PHC services.

The majority (85 percent) of participants were between 20 and 49 years of age (range 18-70); the average age was 29. Most participants (79 percent) identified themselves as being single but in a steady relationship; 11 percent reported being married; 5 percent were single and not in a steady relationship; and a small number reported being divorced or widowed. Most participants (88 percent) had completed at least secondary education, 7 percent of whom had a college/university level education. 


\begin{tabular}{|c|c|c|c|c|}
\hline & \multicolumn{2}{|c|}{$\begin{array}{l}\text { Completing exit } \\
\text { interview }\end{array}$} & \multicolumn{2}{|c|}{$\begin{array}{l}\text { Completing self-administered } \\
\text { interview }\end{array}$} \\
\hline & $\mathrm{N}$ & Percent & $\mathrm{N}$ & Percent \\
\hline Total & 1,227 & 100 & 986 & 100 \\
\hline \multicolumn{5}{|l|}{ Facility } \\
\hline Allamansdrift B & 246 & 20.1 & 244 & 24.75 \\
\hline Boulders & 165 & 13.5 & 60 & 6.09 \\
\hline Fernie 1 & 255 & 20.8 & 241 & 24.44 \\
\hline Marite & 252 & 20.5 & 172 & 17.44 \\
\hline Piet Retief & 309 & 25.2 & 269 & 27.28 \\
\hline \multicolumn{5}{|l|}{ Age group } \\
\hline 18-19 & 132 & 10.8 & 119 & 12.07 \\
\hline $20-24$ & 349 & 28.4 & 302 & 30.63 \\
\hline $25-29$ & 296 & 24.1 & 238 & 24.14 \\
\hline $30-34$ & 190 & 15.5 & 151 & 15.31 \\
\hline $35-39$ & 93 & 7.6 & 74 & 7.51 \\
\hline $40-44$ & 71 & 5.8 & 53 & 5.38 \\
\hline $45-49$ & 43 & 3.5 & 30 & 3.04 \\
\hline $50-70$ & 51 & 4.2 & 17 & 1.72 \\
\hline N/A & 2 & 0.2 & 2 & 0.2 \\
\hline Age: mean (range) & 28.9 & $(18-70)$ & 27.7 & $(18-63)$ \\
\hline \multicolumn{5}{|l|}{ Current relationship status } \\
\hline Single (not in a relationship) & 64 & 5.2 & 50 & 5.07 \\
\hline Single (in a relationship) & 967 & 78.9 & 790 & 80.12 \\
\hline Married & 137 & 11.2 & 104 & 10.55 \\
\hline In a polygamous marriage & 5 & 0.4 & 3 & 0.3 \\
\hline Divorced & 4 & 0.3 & 3 & 0.3 \\
\hline Separated & 8 & 0.7 & 5 & 0.51 \\
\hline Widowed & 20 & 1.6 & 11 & 1.12 \\
\hline Other & 21 & 1.7 & 20 & 2.03 \\
\hline N/A & 1 & 0.1 & 0 & 0 \\
\hline \multicolumn{5}{|c|}{ Highest level of education completed } \\
\hline Primary & 131 & 10.7 & 54 & 5.48 \\
\hline Secondary & 988 & 80.6 & 851 & 86.31 \\
\hline College certificate/diploma & 70 & 5.7 & 62 & 6.29 \\
\hline University degree & 20 & 1.6 & 18 & 1.83 \\
\hline Other & 17 & 1.4 & 1 & 0.1 \\
\hline N/A & 1 & 0.1 & 0 & 0 \\
\hline
\end{tabular}




\section{Health-seeking behavior}

For success in introducing a new HIV-prevention technology, it is important to understand the types of services and outlets that would be most suitable for distributing the particular product. For an ARV-based prevention method for women, such as tenofovir gel, knowing the types of health services women seek, where they go for services, how they would like to receive information and counseling, and what their experiences have been interacting with the health system and health providers are all important factors to consider in determining how to best position a new product.

When women completed the exit interview they were asked to identify which service or services they had come for that day. The two most commonly sought services were well-baby (31 percent) and FP (17 percent), and some women (16.2 percent) reported coming for more than one service (see Table 2).

TABLE 2 Distribution of PHC clients according to type of service sought, by age

\begin{tabular}{lccccc}
\hline Age group & $\begin{array}{c}\text { HIV testing \& } \\
\text { counseling }\end{array}$ & Antenatal care & Family planning & $\begin{array}{c}\text { Well-baby } \\
\text { services }\end{array}$ & Other service \\
\hline $18-19$ & $12(1.0)$ & $19(1.6)$ & $32(2.6)$ & $43(3.5)$ & $31(2.5)$ \\
$20-24$ & $31(2.5)$ & $46(3.8)$ & $68(5.5)$ & $123(10.0)$ & $105(8.5)$ \\
$25-29$ & $31(2.5)$ & $34(2.8)$ & $56(4.6)$ & $108(8.8)$ & $90(7.3)$ \\
$30-34$ & $22(1.8)$ & $13(1.1)$ & $36(2.9)$ & $53(4.3)$ & $77(6.2)$ \\
$35-39$ & $6(0.5)$ & $6(0.5)$ & $11(0.9)$ & $22(1.8)$ & $57(4.6)$ \\
$40-44$ & $6(0.5)$ & $3(0.2)$ & $5(0.4)$ & $17(1.4)$ & $47(3.8)$ \\
$45-49$ & $6(0.5)$ & $0(0.0)$ & $3(0.2)$ & $7(0.6)$ & $34(2.8)$ \\
$50-70$ & $6(0.5)$ & $0(0.0)$ & $0(0.0)$ & $2(<0.1)$ & $0(0.0)$ \\
Total & $120(9.8)$ & $121(10)$ & $211(17.1)$ & $375(30.5)$ & $441(35.7)$ \\
\hline
\end{tabular}

NOTE: Other services included: ARV treatment (7.4\%); care for chronic disease (6.4\%); pregnancy testing (3.4\%); TB treatment (2.4\%); physical injury treatment (2.1\%); PEP, emergency contraception, STI treatment, termination of pregnancy $(<1 \%$ each); and "other" (15.7\%). Two women did not indicate their age.

\section{HIV testing practices}

Use of ARVs such as tenofovir gel for PrEP will require regular HIV testing to ensure users are uninfected before initiating and continuing product use. Thus, understanding HIV testing practices among potential users is critical in planning for introduction. More than 90 percent of the women in the study knew their HIV status and 79 percent had disclosed this information to someone. Of the 1,227 participants who completed the exit interviews, 93 percent reported having been tested for HIV at least once, with significant differences by age group; whereas 94 percent of women aged 25-49 had ever been tested, 83 percent of 18-19 year olds and 82 percent of women 50 and older had ever been tested (chi-square $p$ value $<0.001$ ). Similarly, there were significant differences in the percentage of 18-44 year olds (70 percent) versus women 45 and older (56 percent) who were tested within the last year $(p=0.001)$. Figure 2 shows HIV testing practices according to age group.

Chi-square tests also illustrated significant differences in HIV testing frequency by type of service sought. Among women who came for FP, 69 percent had been tested for HIV more than once in the previous year compared with 59 percent of women who had not come for FP services $(p=0.04)$. Similarly, 69 percent of women seeking well-baby services had been tested more than once in the previous year compared with 56 percent who had not come for wellbaby services ( $p=0.003$ ). On the other hand, 42 percent of women who came for ANC had been tested for HIV more than once in the previous year compared with 63 percent of those who did not come for ANC. Finally, 62 percent of women who had ever been pregnant had been tested more than once in the last year compared with 49 percent of women who had never been pregnant $(p=0.04)$. 
FIGURE 2 HIV TESTING PRACTICES REPORTED BY PHC CLIENTS ON EXIT INTERVIEWS, ACCORDING TO AGE GROUP $(\mathrm{N}=1,227)$

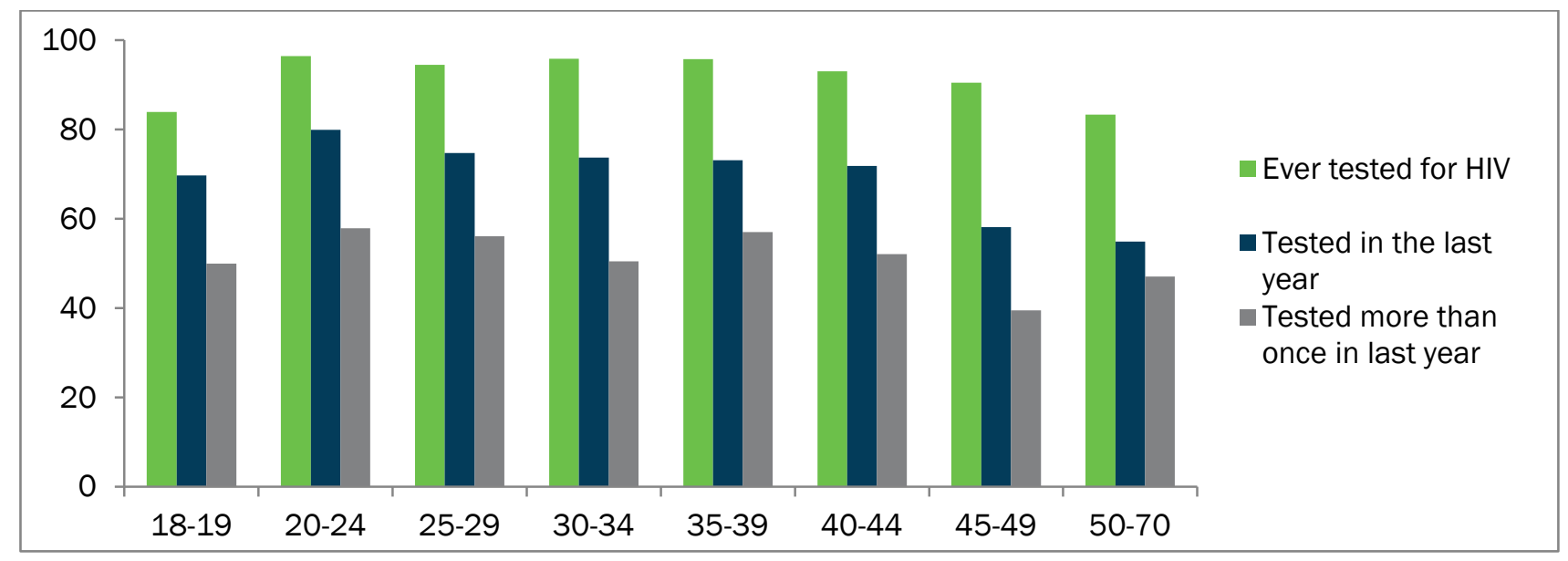

\section{Risk perception}

Of critical importance to the introduction of HIV-prevention products is a more nuanced understanding of women's perception of the risk and actions they are willing and able to take to protect themselves. Several models of health behavior, including the Health Belief Model (Glanz et al. 2002) and the Transtheoretical Model (Brown et al. 1991) include the construct of "risk" as a key element necessary for individual behavior change. Although women's selfassessment of their individual risk of getting HIV may or may not align with their actual risk, gaining a more nuanced understanding of how women characterize their level of risk (low to high) can help to inform prevention efforts.

Women completing the anonymous questionnaire who reported being HIVnegative $(n=766)$ were asked to assess their level of HIV risk (none, low, medium, high, or unknown) and to indicate reasons they believed themselves to be at risk or not. Women's self-assessed risk fell into approximately three categories: those who believed themselves to be at no to low risk (36.4 percent); those who thought they were at medium to high risk (27.4 percent); and those who did not know their risk (26.9 percent).

As shown in Table 3, having only one partner was the most frequently mentioned reason why women felt they were not at risk of getting HIV (39.7 percent). Using condoms every time they had sex (20.2 percent) and getting tested regularly (13.6 percent) were the next most frequently mentioned reasons for believing they were not at risk.
TABLE 3 Reasons women thinking they are not at risk of HIV

\begin{tabular}{lcc} 
Why do you think you are not at risk of & N $=614$ & Percent \\
getting HIV?* & 59 & 9.8 \\
\hline I am not currently sexually active & 240 & 39.7 \\
I have only one partner & 51 & 8.4 \\
I have only ever had one partner & 23 & 3.8 \\
I am married & 122 & 20.2 \\
I use condoms every time I have sex & 37 & 6.1 \\
I trust my partner & 39 & 6.4 \\
My partner shared his status & 82 & 13.6 \\
I get tested for HIV regularly & 3 & 0.5 \\
Other reasons for not being at risk of HIV & 38 & 6.3 \\
\hline Refuse to answer reason for not being at risk & & \\
\hline
\end{tabular}

*Denominator includes women who responded to any of the subsequent reasons for not being at risk.

$* * N$ 's do not add up to $100 \%$ because multiple responses were possible. 
Table 4 shows the key reasons (and their frequency) why women considered themselves to be at risk of getting HIV. Not knowing a partner's HIV status was the most frequently mentioned reason (23.8 percent), followed by worry that their partner has other partners (19.7 percent) and not having used a condom at last vaginal sex (16.6 percent).

\section{Association between composite measure of risk and self-assessed risk}

A composite measure of risk (CMR) of HIV was calculated based on the number of affirmative responses to eight questions on the selfadministered anonymous questionnaire (see Table 5). The CMR was calculated for all women who reported they were HIV negative $(n=766)$ on the anonymous questionnaire, with the exception of those who didn't respond to question about self-assessed risk ( $n=71$ ), making a total of 695 women in the CMR calculation.

TABLE 5 Questions included in the CMR ( $\mathrm{N}=695)$

\begin{tabular}{lrr}
\hline & $\mathrm{N}$ & Percent \\
\hline Don't know own HIV status & 99 & 12.9 \\
Don't know husband or primary partner's HIV status & 349 & 45.6 \\
Husband or primary partner is HIV-positive & 16 & 4.5 \\
Ever had an STI & 129 & 16.8 \\
Never used a condom during vaginal sex & 135 & 17.6 \\
Had anal sex in past 3 months & 112 & 14.6 \\
Partner forced sex in last 12 months & 56 & 7.3 \\
Drank alcohol to the point of getting drunk, last 12 months & 146 & 19.1 \\
\hline
\end{tabular}

assessed as having no risk of HIV had a CMR of 3 or higher, compared to $\mathbf{2 3}$ percent of the women who selfassessed as being at high risk of HIV. The associations between the CMR score and women's self-assessed level of risk was tested with a chi-square test and was highly significant $(p=0.0044)$.

As shown in Table 6, participants in the green highlighted cells (20.3 percent) had a self-assessment similar to their CMR, participants in the orange highlighted cells (26.5 percent) may be overestimating their risk, and participants in the blue highlighted cells (23.6 percent) may be underestimating their HIV risk. Additionally, 29.6 percent of participants did not know their risk.
TABLE 4 Reasons women think they are at risk of getting HIV

\begin{tabular}{lrr} 
Why do you think you are at risk of getting HIV?* & N =605 & Percent \\
\hline I had sex with more than one partner in the past 3 months & 55 & 9.0 \\
I do not know my partner's HIV status & 146 & 23.8 \\
I did not use a condom last time I had vaginal sex & 102 & 16.6 \\
I did not use a condom last time I had anal sex & 48 & 7.8 \\
I am worried that my partner has other partners & 121 & 19.7 \\
I am worried that my partner uses drugs & 8 & 1.3 \\
I am using drugs & 3 & 0.5 \\
I am in a polygamous marriage & 5 & 0.8 \\
I am a sex worker & 3 & 0.5 \\
Sometimes my partner is violent/abusive to me & 9 & 1.5 \\
I sometimes have sex in exchange for goods or money & 7 & 1.1 \\
Other reason for risk of HIV & 10 & 1.6 \\
I don't know & 125 & 20.4 \\
Refuse to answer & 48 & 7.8
\end{tabular}

*Denominator includes women who responded to any of the subsequent reasons for being at risk.

The CMR was divided into categories of risk, based on the number of affirmative responses to the 8 questions, are as follows: no risk (0); low risk (1); medium risk (2), high risk (3-6); no women responded affirmatively to more than six questions.

Chi-square was then used to measure the association between the CMR and self-assessed risk. Among women who self-assessed as having no risk of HIV, 30 percent had a CMR of 0 , meaning they answered "no" to all questions. Eleven percent of the women who self- 
TABLE 6 Self-assessed Risk, by CMR ( $\mathrm{n}=695)$

\begin{tabular}{|c|c|c|c|c|c|c|}
\hline $\begin{array}{l}\text { Composite } \\
\text { measure of risk }\end{array}$ & No risk & Low risk & Medium risk & High risk & Don't know & Total \\
\hline 0 & $43(6.18 \%)$ & 39 (5.61\%) & 13 (1.87\%) & 26 (3.74\%) & 43 (6.19\%) & 164 \\
\hline 1 & 55 (7.9\%) & 48 (6.91\%) & 32 (4.6\%) & 35 (5.04\%) & 78 (11.22\%) & 248 \\
\hline 2 & $29(4.17 \%)$ & $29(4.17 \%)$ & $20(2.88 \%)$ & 39 (5.61\%) & $53(7.63 \%)$ & 170 \\
\hline $3-6$ & $15(2.16 \%)$ & $21(3.02 \%)$ & $15(2.16 \%)$ & 30 (4.32\%) & 32 (4.6\%) & 113 \\
\hline Total & 142 & 137 & 80 & 130 & 206 & 695 \\
\hline
\end{tabular}

Note: 71 women did not respond to the self-assessed risk question and are excluded from the table.

Green=Self-assessment similar to their CMR; Orange=May be overestimating their risk; Blue=May be underestimating their HIV risk.

Although there are limitations to the interpretation of this information in the absence of a biomarker that would provide a more accurate measure of HIV risk, these data contribute important information as to how women assess their level of risk. Women both under- and overestimate their level of risk as calculated by the CMR. Slightly more than half of all women either did not know their risk (29.6 percent) or underestimated their risk (23.6 percent) as per the CMR. Perhaps most worrisome is the women who appear to underestimate their risk, as it is unlikely that a woman who perceives herself to be at low or no risk would be motivated to adopt prevention practices or willing to use an ARV-based prevention product. Only about 20 percent of women seem to have a relatively accurate selfassessment of their risk as measured by the CMR.

\section{OBJECTIVE 2}

Document clients' perspectives on ARV-based prevention and tenofovir gel specifically, including their interest and willingness to try such products in the future.

Very few women said they had ever heard of PrEP (3 percent), vaginal microbicides in general (7 percent), and tenofovir gel specifically ( 8 percent). After being provided with a brief description of tenofovir gel, 94 percent said they would be willing to try it on its own (56 percent) or in combination with another method (39 percent). Other than more generally being interested in a prevention method, the most commonly reported reasons for wanting to try tenofovir gel were not trusting partners (12 percent) or disliking condoms (8 percent). When asked about potential concerns using the gel, 21 percent said they would worry that it might cause side effects; in general, 3 percent were worried specifically about potential side effects for their partners and 3 percent were concerned about harm if one were to get pregnant while using the gel. The majority of women (more than 95 percent) had no concerns about the gel reducing sexual pleasure (for themselves or their partners), although 7 percent said they were concerned it might cause too much wetness.

Most women (92 percent) said they would prefer to get the product from a clinic, preferably from a nurse (80 percent), versus a pharmacy or other outlet, and 68 percent said they would only use it if it were free. The majority (82 percent) thought that a vaginal gel used only around the time of sex would be easier to use than a daily oral pill. When asked how frequently they would be willing to come to a clinic (or elsewhere) for resupply, 53 percent said monthly and 22 percent said every three months. Similarly, half of the women said they would be willing to be tested for HIV every three months if it was a prerequisite for product resupply, and an additional 22 percent said they would be willing to get tested once a month.

\section{OBJECTIVE 3}

Gather insights from a select number of facility and program managers about the potential role that tenofovir gel could play in their programs and the challenges and opportunities of introducing the product.

Semistructured interviews were conducted with facility managers from each of the three districts in Mpumalanga where the study was conducted, and one district manager from Maternal, Child and Women's Health. They shared their thoughts and observations about service provision in general, and specifically in relation to HIV prevention, 
treatment, and care. They were then asked about challenges and opportunities for tenofovir gel introduction. Key insights and themes emerging from the interviews are highlighted.

\section{Service delivery}

Respondents were asked to provide a general description of the services at PHC facilities. While it is not possible to verify the degree to which these services are operational in all centers, below is an overview of the possible constellation of services offered at these facilities.

HIV prevention services:

- provider initiated counseling and testing (PICT)

- voluntary HIV counseling and testing (HCT)

- post-exposure prophylaxis (PEP)

- prevention of mother-to-child transmission (PMTCT)

- provision of male and female condoms

- prevention and treatment of STIS

- cervical cancer screening

- in some settings, medical male circumcision

Services for HIV-positive patients:

- prevention and management of TB

- provision of ARVs

- adherence counseling

- monitoring of CD4 count

- support groups

The overall goal is for all clients attending PHC centers-regardless of reason-to be offered HIV counseling and testing. In principle, HIV prevention is integrated with other services so that all clients are encouraged to be tested; the degree to which this happens in practice is less clear.

While one might expect service-delivery practices to be standardized across PHC clinics, there is variation in how they are rolled out. For example, in the case of PEP, most clinics do not actually offer it. At clinics where PEP is provided for accidental exposure, it is not actively offered; rather it is available for those who are aware of it and seek it out. Even in the case of rape, procedures vary between clinics within the same province. For example, while most clinics provide PEP for rape, some refer women to the police station first to file a report and then refer them to the hospital for PEP and other services. In other cases, the clinic provides PEP to HIV-negative women immediately and then refers them to the hospital for forensic management of rape.

This example highlights the variability in service delivery even within the context of PHC clinics.

\section{HIV testing and retesting practices}

Pregnant women, young people, and women seeking FP reportedly seek out HCT most frequently. Testing practices within ANC services differ among clinics, even within the same province. At one clinic, for example, a new policy was implemented wherein pregnant women were to be tested every six weeks (versus only at first prenatal visit and at 32 weeks). Importantly, even the protocol of testing at 32 weeks was not being consistently implemented. It was not clear whether this was because nurses were not offering the testing or women did not want it.

The general recommendation for PHC clinics is to try to get everyone tested at least once a year. When clients test negative, they are encouraged to return for repeat testing three months later to confirm the negative result. It has proved difficult to follow up with clients for retesting because client registers are no longer being kept. Clients who 
test positive are referred to a variety of services including wellness clinics, adherence counseling, psychosocial support, treatment of opportunistic infections, monitoring of CD4 count and viral load, and, as soon as eligible, initiation of ARV therapy. In some instances, home-based care teams follow up with HIV-positive clients who do not return to the clinic for treatment or monitoring.

\section{Workforce, record-keeping, logistics}

When asked about the challenges to providing high-quality services, most respondents described a lack of human, physical, and financial resources, with an emphasis on the burden on nurses. There are few medical doctors on staff; nurses perform the majority of all services. A few respondents indicated that clients would prefer to receive HCT from a nurse who they are seeing for another service, rather than from a lay counselor who specifically provides $\mathrm{HCT}$, both for confidentiality reasons and convenience.

Shortage of space, heavy client load, and difficulty in providing continuity of care for clients were also seen as challenges. Several respondents described limited space-often only one private room in a clinic-for HCT. Stockouts of supplies, including HIV test kits, was noted as a problem but one that could be alleviated with better forecasting. There was an overall sense of frustration on the part of clinic staff regarding record-keeping. Although registers are used, the information that is captured is not comprehensive, not always accurate, and is variable from one site to another. Only one clinic has an electronic system (Tier 2) that captures information on all clients coming for HCT and their HIV test results

Despite these challenges, respondents indicated that in general clients are pleased with the quality of actual services received but are frustrated by long wait times, and distance and travel time to the clinic.

\section{Program managers' attitudes toward tenofovir gel/microbicides}

Given that most of the respondents had little knowledge of microbicides or tenofovir gel, the study team provided standard information and basic facts about microbicides, and tenofovir gel specifically. Despite the inherent challenges of asking about attitudes and opinions concerning products that are not yet available, useful information was gleaned from this select group of program managers. Specifically, program managers were asked about whether this was a product they could envision providing, and if so, where and to whom.

- Most thought it would be best to offer such a product within the context of routine services, the way HCT is offered to anyone coming to PHC facilities, including within FP clinics. There was a clear recognition that married women and those coming for FP are in need of protection.

- Opinions ranged as to whether tenofovir gel would be most beneficial for young people, married women, sex workers, or any woman who considers herself at risk.

When asked about the concerns they might have in offering tenofovir gel, several issues emerged. For example, some expressed concern about:

- The regimen itself (e.g., the understanding that the gel would have to be applied 12 hours prior to sex), maintaining adequate supplies, and how clients would store the product at home.

- The potential of users abandoning the condom for gel (condom migration);

- The type, severity, and likelihood of side-effects; and whether HIV drug resistance was a concern.

Respondents felt they needed more information about:

- The safety of the gel; when it could and should be applied.

- Whether there was an age limit (e.g., whether older women could use it).

- Whether it could be used by women who are pregnant, menstruating, or who had an active STI.

- How often it could be used, for what length of time, and whether it could protect over multiple sex acts.

None of the respondents were aware of the intravaginal rings (IVRs) being tested for HIV prevention. When asked if they thought the gel or an IVR would be preferable, most thought a gel would be preferred, if only because it was something that was more easily understood. There was an assumption that the gel would be easier to apply (if it 
came with an applicator) and that the IVR was likely to be less acceptable to male partners who might feel it during sex. 


\section{IMPLICATIONS FOR INTRODUCTION OF ARV-BASED PREVENTION PRODUCTS FOR WOMEN}

Although this study was focused on the potential introduction of tenofovir gel, the lessons and insights are relevant to the introduction and planning of any ARV-based prevention product for women. While intentionality does not necessarily translate into actual use, the fact that the vast majority of women said that they would be "willing to try" tenofovir gel, despite having never heard of it prior to the study, suggests some level of interest.

Regardless of the future of tenofovir gel, this study provides valuable information regarding women's assessment of their individual HIV risk, testing practices, and service- delivery patterns. Given that most women came to the clinics for FP, ANC, or HCT, identifying effective ways to integrate any new ARV-based prevention product into these types of services would be useful. Further, women who attended FP and/or well-baby services tended to have been tested more often than those seeking other services. This suggests that repeat testing is possible, particularly if done within the context of these services. The data on HIV-testing patterns is important as it indicates that many women are already being tested regularly for HIV-a prerequisite for provision of any ARV-based prevention product. Finally, program managers provided important suggestions for readying health systems for a new ARV-based prevention product, including establishing awareness-raising campaigns, training providers (particularly nurses), and educating the community, including men, about HIV-prevention practices in general and about new products specifically. 


\section{REFERENCES}

Abdool Karim, Q., et al. 2010. "Effectiveness and safety of tenofovir gel, an antiretroviral microbicide, for the prevention of HIV infection in women," Science 329:1168-1174.

AIDSTAR-One. 2012. HIV prevention knowledge base. Biomedical interventions: post-exposure prophylaxis (PEP).

Baeten, J.M., et al., for the Partners PrEP Study Team. 2012. "Antiretroviral prophylaxis for HIV prevention in heterosexual men and women," NEJM 367(5):399-410.

Brown, L.K., R.J. DiClemente, and L.A. Reynolds. 1991. "HIV prevention for adolescents: Utility of the Health Belief Model," AIDS Educ Prev 3(1):50-59.

Glanz, K., Rimer, B.K., Lewis, F.M. (eds.). 2002. Health Behavior and Health Education: Theory, Research and Practice, 3rd Edition. San Francisco, CA: John Wiley and Sons.

Grant, R.M., et al. 2010. "Preexposure chemoprophylaxis for HIV prevention in men who have sex with men," NEJM 363(27):2587-2599.

Hayes, R.J. and Moulton, L.H. 2009. Cluster Randomised Trials. Chapman \& Hall/CRC Press.

National Department of Health, South Africa. 2010. The National Antenatal Sentinel HIV \& Syphilis Prevalence Survey.

PEPFAR. 2011. Guidance for the Prevention of Sexually Transmitted HIV Infections. Washington, DC: The U.S. President's Emergency Plan for AIDS Relief (PEPFAR).

South African Medical Research Council. 2014. Geographic Information Systems department, Durban, South Africa.

Steen, R. et al. 2009. "Control of sexually transmitted infections and prevention of HIV transmission: Mending a fractured paradigm,” Bull WHO 87: 858-865.

Thigpen, M.C. et al. 2012. "Antiretroviral preexposure prophylaxis for heterosexual HIV transmission in Botswana." NEJM 367(5):423-434. Epub 2012/07/13.

UNAIDS. 2013. Global Report: UNAIDS Report on the Global AIDS Epidemic. Geneva: Joint United Nations Programme on HIV/AIDS.

UNAIDS. 2014. Progress Report on the Global Plan Towards the Elimination of New HIV Infections Among Children by 2015 and Keeping Their Mothers Alive. Geneva: Joint United Nations Programme on HIV/AIDS.

USAID. 2011. Proposal for a Shared Vision and Strategic Plan for Microbicide Introduction. 


\section{Appendix: Description of the Five Study Clinics}

\begin{tabular}{|c|c|c|c|c|c|}
\hline \multirow[b]{2}{*}{ District } & \multicolumn{5}{|c|}{ CLINIC } \\
\hline & Boulders & Marite & Allamansdrift B & Piet Retief & Fernie 1 \\
\hline Setting & Rural & Rural & Rural & Urban & Rural \\
\hline Hours & M-F; 8am-4pm & 7 days/week; $7 \mathrm{am}-4 \mathrm{pm}$ & M-F; 7am-4pm & M-F; 7am-4pm & 7 days/week; $7 \mathrm{am}-7 \mathrm{pm}$ \\
\hline Staffing & $\begin{array}{l}\text { - } 5 \text { Professional nurses } \\
\text { (PNs) } \\
\text { - } 2 \text { Enrolled nurses } \\
\text { (ENs) } \\
\text { - } 2 \text { Lay counselors } \\
\text { - } 1 \text { General assistant } \\
\text { - } 1 \text { Gardener } \\
1 \text { Medical doctor } \\
\text { (MD) (comes once } \\
\text { per week) }\end{array}$ & $\begin{array}{l}\text { - } 6 \text { PNs } \\
\text { - } 3 \text { ENs } \\
\text { - } 1 \text { Nursing assistant } \\
\text { (NA) } \\
\text { - } 1 \text { Data capturer } \\
\text { - } 3 \text { Lay counselors } \\
\text { - } 1 \text { General assistant }\end{array}$ & $\begin{array}{l}\text { - } 3 \text { PNs } \\
\text { - } 1 \text { EN } \\
\text { - } 1 \text { NA } \\
\text { - } 1 \text { Data capturer } \\
\text { - } 1 \text { Lay counselor } \\
\text { - } 1 \text { General assistant } \\
\text { - } 1 \text { Gardener } \\
\text { - } 12 \text { Home-based care- } \\
\text { givers }\end{array}$ & $\begin{array}{l}\text { - } 11 \text { PNs } \\
\text { - } 3 \text { Staff nurses } \\
\text { - } 3 \text { Lay counselors } \\
\text { - } 1 \text { Data capturer } \\
\text { - } 1 \text { GA } \\
\text { - } 1 \text { Groundsman } \\
\text { - } 2 \text { Volunteers } \\
\text { Outreach team (1 PN, } 2 \\
\text { CHW) }\end{array}$ & $\begin{array}{l}\text { - } 4 \text { PNs } \\
\text { - } 1 \text { EN } \\
\text { - } 3 \text { NAs } \\
\text { - } 2 \text { Administrative clerks } \\
\text { - } 2 \text { Clerks } \\
\text { - } 2 \text { GAs } \\
\text { - } 3 \text { Lay counselors }\end{array}$ \\
\hline Services & $\begin{array}{l}\text { - ANC } \\
\text { - Chronic diseases } \\
\text { - Delivery } \\
\text { - Minor ailments } \\
\text { - PNC } \\
\text { - SRH } \\
\text { - TB } \\
\text { - Well-baby } \\
\text { - Wellness }\end{array}$ & $\begin{array}{l}\text { - Chronic diseases } \\
\text { - Delivery } \\
\text { - Minor ailments } \\
\text { - PNC } \\
\text { - SRH } \\
\text { - TB } \\
\text { - Well-baby } \\
\text { - Wellness }\end{array}$ & $\begin{array}{l}\text { - ANC } \\
\text { - Cancer screening } \\
\text { - Chronic disease } \\
\text { - Emergency deliveries } \\
\text { only } \\
\text { - Family planning } \\
\text { - Minor ailments } \\
\text { - PNC } \\
\text { - SRH (Pregnancy } \\
\text { testing, TOP } \\
\text { counseling, referrals) } \\
\text { - STI } \\
\text { - TB }\end{array}$ & $\begin{array}{l}\text { - ANC } \\
\text { - Cancer screening } \\
\text { - Chronic disease } \\
\text { - EPI, child health, } \\
\text { nutrition; food parcels as } \\
\text { needed } \\
\text { - Family planning } \\
\text { - Minor ailments } \\
\text { - PNC } \\
\text { STI } \\
\text { - TB }\end{array}$ & $\begin{array}{l}\text { - ANC and PMTCT } \\
\text { - Chronic diseases } \\
\text { - Delivery } \\
\text { - Family planning } \\
\text { - Minor ailment } \\
\text { - PNC } \\
\text { - SRH } \\
\text { - TB } \\
\text { - Well-baby } \\
\text { - Wellness }\end{array}$ \\
\hline $\begin{array}{l}\text { Family } \\
\text { planning } \\
\text { methods } \\
\text { offered }\end{array}$ & $\begin{array}{l}\text { - Injectables } \\
\text { - Oral contraceptives } \\
\text { (OCs) } \\
\text { - Male and female } \\
\text { condoms }\end{array}$ & $\begin{array}{l}\text { - Injectables } \\
\text { - OCs } \\
\text { - Male and female } \\
\text { condoms }\end{array}$ & $\begin{array}{l}\text { - Injectables } \\
\text { - OCs } \\
\text { - Male and female } \\
\text { condoms } \\
\text { - Implant and IUDs- } \\
\text { introduced but } \\
\text { stopped a few months } \\
\text { later }\end{array}$ & $\begin{array}{l}\text { - Injectables } \\
\text { OCs } \\
\text { - Male and female } \\
\text { condoms }\end{array}$ & $\begin{array}{l}\text { - Injectables } \\
\text { - OCs } \\
\text { - Male and female } \\
\text { condoms } \\
\text { - Implant and IUDs- } \\
\text { introduced but } \\
\text { stopped a few months } \\
\text { later }\end{array}$ \\
\hline
\end{tabular}




\begin{tabular}{|c|c|c|c|c|c|}
\hline $\begin{array}{l}\text { HIV services } \\
\text { offered }\end{array}$ & $\begin{array}{l}\text { HCT and Rx PrEP } \\
\text { provided by } 2 \text { lay } \\
\text { counselors. } \\
\text { Rx provided by MD } \\
\text { and PNs. } \\
\text { Lay counselors do } \\
\text { follow-up and } \\
\text { adherence assess- } \\
\text { ments. } \\
\text { PEP provided for } \\
\text { sexual assault or } \\
\text { rape; survivors } \\
\text { assessed and } \\
\text { referred to hospital. }\end{array}$ & $\begin{array}{l}\text { HCT and treatment } \\
\text { PrEP provided by } 3 \text { lay } \\
\text { counselors. } \\
\text { After clients start } \\
\text { ARVs, seen by } \\
\text { providers attending to } \\
\text { all chronic care. } \\
\text { - PEP provided for } \\
\text { sexual assault or rape; } \\
\text { survivors assessed } \\
\text { and referred to } \\
\text { hospital for PEP. } \\
\text { PEP provided for burst } \\
\text { condom; offered by } \\
\text { PNs. }\end{array}$ & $\begin{array}{l}\text { HTC. } \\
\text { HIV care and support. } \\
\text { ARV provision. } \\
\text { PEP offered for rape, } \\
\text { sexual assault, and } \\
\text { burst condoms. }\end{array}$ & $\begin{array}{l}\text { HTC. } \\
\text { HIV care and support. } \\
\text { - ARV provision. } \\
\text { PEP offered for rape, } \\
\text { sexual assault, and burst } \\
\text { condoms. } \\
\text { - Services provided in } 2 \\
\text { consulting rooms by } \\
\text { counselors and } 1 \text { nurse. }\end{array}$ & $\begin{array}{l}\text { - HTC. } \\
\text { - ARV treatment. } \\
\text { - HIV care and support. } \\
\text { - PEP for sexual assault } \\
\text { or rape; survivors } \\
\text { referred to MD who } \\
\text { provides PEP. } \\
\text { - PEP for burst condom } \\
\text { is offered by PNs. } \\
\text { MCC is done } 1 \\
\text { day/week by MD from } \\
\text { nearby provisional } \\
\text { hospital. } \\
\text { Services are provided } \\
\text { by the counselors, who } \\
\text { work in shifts and are } \\
\text { available at the clinic } \\
\text { throughout the day. } \\
\text { There are } 2 \text { rooms } \\
\text { available for HCT. }\end{array}$ \\
\hline $\begin{array}{l}\text { Other } \\
\text { noteworthy } \\
\text { information }\end{array}$ & $\begin{array}{l}30 \text { people/day } \\
\text { Mostly adults; mainly } \\
\text { female. }\end{array}$ & $\begin{array}{l}\text { 4,000 clients/month. } \\
\text { Mostly adults; more } \\
\text { females. } \\
\text { Busy all day. } \\
3 \text { buildings: } 1 \text { for } \\
\text { chronic treatments } \\
\text { (incl. HIV and TB), } \\
\text { minor ailments, SRH; } 1 \\
\text { for well-baby, ANC; } 1 \\
\text { for HCT. } \\
\text { Works with local CBOs } \\
\text { for outreach. }\end{array}$ & $\begin{array}{l}\text { 1,300 clients/month } \\
\text { Mostly adults, but } \\
\text { more females } \\
\text { All services every day } \\
\text { of the week }\end{array}$ & $\begin{array}{l}\text { Small clinic; limited } \\
\text { space. } \\
\text { Very busy in the morning. } \\
\text { - Long wait times. }\end{array}$ & $\begin{array}{l}\text { Approximately } 100 \\
\text { clients/day. } \\
\text { More females and } \\
\text { older clients than } \\
\text { males and young } \\
\text { people. }\end{array}$ \\
\hline
\end{tabular}

$\mathrm{PN}=$ Professional nurse; $\mathrm{EN}=$ Enrolled nurse; $\mathrm{GA}=$ General assistant; $\mathrm{MD}=$ Medical doctor; NA = Nursing assistant; $\mathrm{CHW}=$ Community health worker; $\mathrm{ANC}=$ Antenatal care; $\mathrm{PNC}=$ Postnatal care; $\mathrm{EPI}=$ Expanded program on immunization; $\mathrm{MMC}=$ Medical male circumcision. $\mathrm{CBO}=\mathrm{Community}-\mathrm{based}$ organization; $\mathrm{OC}=$ Oral contraceptive. 
Population Council One Dag Hammarskjold Plaza New York, New York 10017 USA Tel: 1-212-339-0500 